J. Lake Sci.(湖泊科学), 2017, 29(4): 887-895

DOI 10. 18307/2017. 0412

(C) 2017 by Journal of Lake Sciences

\title{
外源溶解性有机碳对抚仙湖甲壳类浮游动物碳源的贡献
}

\author{
孙 欢 $^{1,2}$, 张永东 ${ }^{1}$, 于谨磊 ${ }^{1}$, 胡金润 ${ }^{3}$, 刘 正文 ${ }^{1,3}$, 苏雅玲 ${ }^{1 * *}$ \\ (1: 中国科学院南京地理与湖泊所湖泊与环境国家重点实验室,南京 210008) \\ (2: 中国科学院大学, 北京 100043) \\ (3:暨南大学,广州 510632)
}

\begin{abstract}
摘 要: 外源溶解性有机碳 (DOC) 是湖泊碳库的重要组成部分, 关于外源 DOC 对浮游动物的贡献及途径需要深人研究. 本研究在抚仙湖受控实验中添加 ${ }^{13} \mathrm{C}$ 标记的葡萄糖, 通过分析样品中浮游植物与浮游动物的种类、数量、磷脂脂肪酸生物 标志物及其稳定同位素特征, 研究外源 DOC 对湖泊甲壳类浮游动物碳源的贡献比例及其变化. 结果表明: 细菌、甲壳类浮 游动物 (象鼻溞) 的 $\delta^{13} \mathrm{C}$ 值在加人葡萄糖后分别从- $16.28 \%$ 和 $-23.88 \%$ 快速增加到 $5408.25 \%$ 和 $1974.7 \%$, 而藻类磷脂脂 肪酸 ( $\mathrm{C} 18: 2 \omega 6) \delta^{13} \mathrm{C}$ 值从- $27.07 \%$ 增加到 $342.44 \%$, 增长的幅度表明添加的葡萄糖首先被细菌和浮游动物快速利用, 而 藻类只利用了一小部分. 同时细菌、颗粒性有机物 $(\mathrm{POM})$ 和浮游动物的 $\delta^{13} \mathrm{C}$ 值在第 $1 \mathrm{~d}$ 急剧增加, 细菌的 $\delta^{13} \mathrm{C}$ 值远大于 浮游动物和 POM 的 $\delta^{13} \mathrm{C}$ 值, 之后细菌和 POM 的 $\delta^{13} \mathrm{C}$ 值开始下降, 但浮游动物的 $\delta^{13} \mathrm{C}$ 值却仍在缓慢增加, 进一步表明了 DOC 进入湖泊后首先被细菌吸收利用, 而细菌吸收 DOC 后通过自身代谢作用形成细胞颗粒, 浮游甲壳类动物通过摄食 细胞颗粒来获得外源 DOC.
\end{abstract}

关键词: 外源溶解性有机碳; ${ }^{13} \mathrm{C}$ 标记; 碳源; 甲壳类浮游动物; 磷脂脂肪酸; 抚仙湖

\section{Contribution of allochthonous dissolved organic carbon to the carbon source of planktonic crustaceans in Lake Fuxian}

\author{
SUN Huan ${ }^{1,2}$, ZHANG Yongdong ${ }^{1}$, YU Jinlei ${ }^{1}$, HU Jinrun ${ }^{3}$, LIU Zhengwen ${ }^{1,3} \&$ SU Yaling ${ }^{1 * *}$ \\ (1: State Key Laboratory of Lake Science and Environment, Nanjing Institute of Geography and Limnology, Chinese Academy \\ of Sciences, Nanjing 210008, P.R.China) \\ (2: University of Chinese Academy of Sciences, Beijing 100043, P.R.China) \\ (3: Jinan University, Guangzhou 510632, P.R.China)
}

\begin{abstract}
Allochthonous dissolved organic carbon (DOC) is of importance in lake carbon stock, therefore, the contribution and pathways of allochthonous DOC to planktonic crustaceans deserves further study. A controlled experiment was performed through adding glucose labeled with $\delta^{13} \mathrm{C}$ in water from Lake Fuxian. By analyzing the samples of phytoplankton and zooplankton species, quantity and phospholipid fatty acid (PLFA) biomarkers and their carbon stable isotope, the contribution of allochthonous DOC to crustacean zooplankton carbon source was investigated. The results showed that after adding glucose, $\delta^{13} \mathrm{C}$ values of bacteria and planktonic crustaceans (Bosmina) increased rapidly from $-16.28 \%$ to $5408.25 \%$ and $-23.88 \%$ to $1974.7 \%$, respectively, whereas the $\delta^{13} \mathrm{C}$ value of chlorophyceae increased from $-27.07 \%$ to $342.44 \%$. The growth rate showed that bacteria and zooplankton firstly utilized the adding glucose. The $\delta^{13} \mathrm{C}$ values of bacteria, particulate organic matter (POM) and zooplankton increased sharply at the first day, moreover, the $\delta^{13} \mathrm{C}$ value of bacteria is much higher than that of zooplankton and POM. After the first day, $\delta^{13} \mathrm{C}$ values of bacteria and POM decreased, by contrast, zooplankton $\delta^{13} \mathrm{C}$ value increased slowly. This suggests that allochthonous DOC is firstly utilized by bacteria and form cell particles via the metabolism of bacteria. Subsequently, planktonic crustaceans can utilize allochthonous DOC by grazing cell particles.
\end{abstract}

Keywords: Allochthonous dissolved organic carbon; ${ }^{13} \mathrm{C}$ labeling; carbon source; planktonic crustaceans; phospholipid fatty

* 国家自然科学基金项目 (31370478, 31670461) 资助. 2016-06-30 收稿;2016-10-09 收修改稿. 孙欢 (1990 ), 女,硕士研究生;E-mail:871401864@ qq.com.

** 通信作者;E-mail: ylsu@ niglas.ac.cn. 
acid; Lake Fuxian

湖泊与流域之间能量与物质的交换是湖沼学研究的核心内容之一. 已有的研究表明湖泊消费者所需的 物质和能量不仅来源于湖泊中以浮游植物为主 (也包括底栖藻类、大型水生植物等) 的内源有机碳; 还可能 来源于湖泊外的输人, 即外源有机碳 ${ }^{[1]}$. 外源有机碳随地表径流等过程进入湖泊, 并以溶解有机碳 (DOC) 和 颗粒有机碳 (POC) 的形式成为湖泊外源碳库的主要组成部分. 作为地球水圈有机碳的主要载体和生物体的 主要底物, DOC 占湖泊总有机碳量的 $80 \% \sim 90 \%{ }^{[2]}$, 在控制水生态系统的物理、化学、生物性质中起着重要 的作用.

浮游甲壳动物主要包括桡足类和枝角类, 是影响湖泊生态系统结构与功能的关键类群. 一直以来, 人们 普遍认为浮游动物的能量 (有机碳) 主要来自湖泊中的内源有机碳一一浮游植物, 但是高原深水湖泊的内源 有机碳通常较少, 而外源有机碳对湖泊碳库的补给作用较为明显 ${ }^{[2]}$. 浮游动物既是细菌和浮游植物的牧食 者, 又是鱼类的捕食对象. 国内的研究主要集中在富营养化严重的浅水湖泊,而在沿岸带较少的高原深水湖 泊, 浮游动物作为湖泊生态系统中的主要初级消费者, 在影响湖泊的水质、初级生产力以及食物网结构等方 面扮演着重要角色. 在贫营养的高原深水湖泊中, 外源有机碳对浮游动物的贡献如何? 利用途径如何? 这 些问题在近期才受到人们的关注 ${ }^{[3-5]}$, 目前, 在这方面的研究已经取得了一些进展, 而这些进展的获得主要 得益于稳定同位素技术在生态学和环境科学领域的应用 ${ }^{[6]}$.

稳定同位素标记法是将生物标记法与稳定同位素技术相结合的一种新的研究方法, 目前已经被应用到 微生物群落结构、食物网等多个领域的研究中. 生物标记物是由某一种或者某一类生物合成的特征性有机 化合物 ${ }^{[7]}$, 在生态学领域常用的生物标志物主要是脂肪酸类. 脂肪酸是细胞膜的重要组分, 由于在食物链传 递过程中该组分可以保持结构不变, 且不同构型的脂肪酸可以指示不同类的生物, 例如细菌、硅藻、甲藻、绿 藻等, 因此利用脂肪酸的特异性可以有效指示食物网结构特征. 例如, Boschker 等 ${ }^{[8]}$ 利用磷脂脂肪酸 (PLFA) 的同位素值研究了 Scheldt 河口春季水华期间的浮游生物的群落结构, 发现绿藻和硅藻的混合群落 占据主导地位, 中间盐度区主要是硅藻水华, 河口下游自养区硅藻水华生物量低于上游河口非自养区. 此 外, 葡萄糖作为生物体内新陈代谢不可或缺的营养物质, 以葡萄糖为示踪剂为微生物对碳源的代谢机理研 究提供了一个科学有效的途径 ${ }^{[9]}$. Ziegler 等 ${ }^{[10]}$ 将 ${ }^{13} \mathrm{C}$ 标记的葡萄糖加人土壤进行短期培养, 并应用 GCIRMS 分析技术测定 PLFAs 的稳定同位素组成, 研究土壤微生物对葡萄糖 C 的循环利用情况. 石宁宁等 ${ }^{[11]}$ 利用 ${ }^{13} \mathrm{C}$ 标记葡萄糖分析 $\gamma$-聚谷氨酸的代谢途径, 证明了葡萄糖主要用于能量代谢和菌体合成, 只有少量参 与了 $\gamma$-PGA 合成, 而谷氨酸为 $\gamma$-PGA 单体的主要来源.

抚仙湖是一个大型贫营养湖泊, 近年来由于人类的频繁活动, 流域岸边的生态植被被破坏, 大量的外源 物质随径流流人湖泊而导致抚仙湖的外源碳增加, 并且抗仙湖水体有机营养物质逐年升高, 浮游植物生物 量增加了 7 10 倍, 透明度下降了 $2.7 \mathrm{~m}$, 综合营养状态指数上升了 2.1 倍 ${ }^{[12]}$, 但整体而言该湖仍为贫营养状 态. 通常, 外源有机碳对贫营养湖泊生产力的影响更为显著. 该类湖泊中外源输人有机碳是否会被浮游动物 利用以及相关的利用途径尚缺少研究. 本研究将 ${ }^{13} \mathrm{C}$ 标记的葡萄糖作为外源 DOC 代表物, 将其加人抚仙湖 水样中进行野外原位控制实验. 通过分析样品中浮游植物与浮游动物的种类、数量、PLFA 生物标志物及其 稳定同位素特征, 研究外源 DOC 对湖泊甲壳类浮游动物碳源的贡献比例及其变化. 研究结果对于了解湖泊 流域物质能量交换和相关途径具有重要参考价值.

\section{1 材料与方法}

\section{1 湖泊背景介绍}

抚仙湖 ( $24^{\circ} 21^{\prime} 28^{\prime \prime} \sim 24^{\circ} 38^{\prime} 00^{\prime \prime} \mathrm{N}, 102^{\circ} 49^{\prime} 12^{\prime \prime} \sim 102^{\circ} 57^{\prime} 26^{\prime \prime} \mathrm{E}$ ) 位于云南省东部的滇中盆地中心, 面积 212 $\mathrm{km}^{2}$, 海拔 $1722 \mathrm{~m}$, 最大水深 $157.3 \mathrm{~m}$, 是我国典型的高原深水湖泊 ${ }^{[13]}$. 抚仙湖为贫营养型湖泊, 水质清澈透 明, 含沙量很小, 湖水中各生物营养元素浓度很低, 生物生产力较低 ${ }^{[14]}$. 近年来, 湖区水质出现富营养化加 速的发展趋势, 湖区内出现了 II 类水, 透明度明显下降 ${ }^{[15]}$.

\section{2 研究方法}

2013 年 6-7 月在抚仙湖北部湖区 (澄江县) 同步采集 $0 \sim 5 \mathrm{~m}$ 混合水样, 分别装人 18 个 $100 \mathrm{~L}$ 的桶中, 
分为 6 组, 每组设 3 个平行. 不添加 ${ }^{13} \mathrm{C}$ 标记的葡萄糖为对照组; 5 个实验组分别对应添加 ${ }^{13} \mathrm{C}$ 标记的葡萄糖 后第 $1 、 3 、 6 、 9$ 和第 $12 \mathrm{~d}$, 每桶添加葡萄糖量为 $30 \mathrm{mg} .{ }^{13} \mathrm{C}$ 标记的葡萄糖初始的碳同位素比值在 $99 \%$ 以上.

用 $5 \mathrm{~L}$ 柱状采水器采集桶中水样, 取 $50 \mathrm{ml}$ 水样用于测定总氮 ( TN) 、总磷 ( TP )、溶解性总氮 (DTN)、溶 解性总磷 (DTP) 浓度; 2 L 水样经由 Whatman GF/C 膜过滤, 用于测定叶绿素 a ( Chl.a) 浓度; 取 $500 \mathrm{ml}$ 水样, 立即加人 $5 \mathrm{ml}$ 鲁哥试剂固定, 用于浮游植物定量分析; 用 $30 \mu \mathrm{m}$ 浮游生物网过滤 $5 \mathrm{~L}$ 水样, 加人 $2 \mathrm{ml}$ 甲醛溶 液固定, 用于浮游动物定量分析; 分批取 $2 \mathrm{~L}$ 水样在 $\mathrm{GF} / \mathrm{F}$ 膜上过滤 $\left(\Phi 47 \mathrm{~mm}\right.$, 预先 $450^{\circ} \mathrm{C}$ 灼烧 $5 \mathrm{~h}$ ), 分别用 于颗粒有机物 (POM) 与细菌和藻类磷脂脂肪酸 (PLFA) 的碳稳定同位素测定, 过滤好的 GF/F 膜立刻放人 冰箱 $-20^{\circ} \mathrm{C}$ 冷冻保存, 带回实验室处理. $\mathrm{GF} / \mathrm{F}$ 膜过滤后的水样经 $48^{\circ} \mathrm{C}$ 烘干浓缩成残渣, 获得溶解性有机物 (DOM) 样品.

\section{3 分析方法}

1.3.1 水体理化指标测定 实验期间用 YSI 多参数水质剖面仪 (Yellow Spring Instruments, USA) 获取桶内水体 温度、电导率 (Cond.) 、氧化还原电位 ( ORP)、 $\mathrm{pH}$ 值、溶解氧 ( DO) 等数据, 结果见表 1. 期间天气状况较为稳定, 桶内水体温度逐步由 $20.9 \pm 0.07$ 升至 $29.06 \pm 0.17^{\circ} \mathrm{C}$, DO 含量变化范围为 $97.60 \% \pm 0.17 \% \sim 108.67 \% \pm 6.16 \%$ 。

表 1 实验组水样理化特征

Tab.1 Physical and chemical properties of experimental groups

\begin{tabular}{|c|c|c|c|c|c|c|c|}
\hline 时间 & 编号 & $\begin{array}{c}\text { 温度/ } \\
{ }^{\circ} \mathrm{C}\end{array}$ & $\begin{array}{l}\text { 电导率/ } \\
(\mu \mathrm{S} / \mathrm{m})\end{array}$ & $\mathrm{pH}$ & $\begin{array}{c}\mathrm{ORP} / \\
\mathrm{mV}\end{array}$ & $\begin{array}{c}\mathrm{DO} / \\
\%\end{array}$ & 水深 $/ \mathrm{m}$ \\
\hline 6 月 29 日 & T0 & $20.90 \pm 0.07$ & $0.28 \pm 0.001$ & $8.24 \pm 0.08$ & $117.00 \pm 1.31$ & $97.60 \pm 0.17$ & 0.51 \\
\hline 6 月 30 日 & $\mathrm{T} 1$ & $24.41 \pm 0.19$ & $0.30 \pm 0.003$ & $8.08 \pm 0.16$ & $107.23 \pm 1.37$ & $108.67 \pm 1.09$ & 0.53 \\
\hline 7 月 2 日 & $\mathrm{T} 3$ & $23.78 \pm 0.18$ & $0.30 \pm 0.001$ & $8.43 \pm 0.15$ & $113.60 \pm 3.73$ & $112.23 \pm 1.06$ & 0.52 \\
\hline 7 月 5 日 & T6 & $25.54 \pm 0.01$ & $0.31 \pm 0.002$ & $8.06 \pm 0.02$ & $117.70 \pm 8.06$ & $96.17 \pm 0.65$ & 0.52 \\
\hline 7 月 8 日 & $\mathrm{T} 9$ & $27.69 \pm 0.19$ & $0.33 \pm 0.001$ & $8.10 \pm 0.02$ & $103.60 \pm 1.21$ & $95.00 \pm 1.00$ & 0.50 \\
\hline 7 月 11 日 & $\mathrm{T} 12$ & $29.06 \pm 0.17$ & $0.35 \pm 0.004$ & $8.63 \pm 0.02$ & $64.33 \pm 6.16$ & $108.67 \pm 6.16$ & 0.49 \\
\hline
\end{tabular}

1.3.2 营养盐指标测定 TN 、TP、DTN、DTP 浓度采用联合消解方法消解, 紫外光催化一过硫酸钾氧化分光光 度法进行测定 ${ }^{[16]}$. Chl.a 浓度经 Whatman $(\mathrm{GF} / \mathrm{C})$ 滤膜过滤, 用乙醇萃取分光光度法测定 ${ }^{[17]}$.

1.3.3 浮游生物定性与定量分析 浮游植物和浮游动物采用 Utermöhl 计数法 ${ }^{[18]}$, 将采集的水样静置浓缩 $48 \mathrm{~h}$ 后, 用细小虹吸管吸取上清液, 浓缩至 $30 \mathrm{ml}$, 并加 $2 \mathrm{ml}$ 福尔马林溶液保存于 $50 \mathrm{ml}$ 的塑料瓶中, 计数前 将样品充分摇勺. 浮游植物取 $0.1 \mathrm{ml}$ 样品于 $0.1 \mathrm{ml}$ 的计数框中, 采用表面苂光显微镜 (Zeiss Axiovent $135 \mathrm{M}$, Germany) 在 $10 \times 40$ 倍视野下进行计数; 浮游动物样品用宽口吸管吸取 $5 \mathrm{ml}$, 注人大型浮游动物计数框中, 在 $10 \times 4$ 倍视野下进行计数, 计数 3 片, 取其平均值, 最后将视野内的浮游植物和浮游动物个数换算成每升水样 中所含浮游植物 ( cells $/ \mathrm{L}$ ) 或浮游动物的数量 ( ind./L). 浮游植物与浮游动物以每升水所含浮游植物或浮游 动物的数量来表示密度. 浮游植物和浮游甲壳动物种类的鉴定参考《淡水浮游生物研究方法》 ${ }^{[19-22]}$.

1.3.4 稳定碳同位素测定 POM/DOM 的碳同位素测定 POM 与 DOM 样品研磨至粉末状,均经同位素质谱仪 (Delta Plus, Finnigan) 测定其碳稳定同位素含量.

浮游动物的碳同位素: 用 $30 \mu \mathrm{m}$ 浮游生物网过滤足量的甲壳类浮游动物, 放人装有蒸馏水的烧杯中, 在 $15 \sim 25^{\circ} \mathrm{C}$ 条件下放置 $5 \mathrm{~h}$ 以清空浮游动物肠道内含物. 随即在解剖镜下手工将浮游动物分类 (主要挑选大型 枝角类、桡足类), 每种类型挑选足够数量的样品装人锡囊中, 冷冻保存 $\left(-20^{\circ} \mathrm{C}\right)$. 带回实验室经冷冻干燥 后,采用同位素质谱仪 (Delta Plus, Finnigan) 测定其稳定碳同位素值.

磷脂脂肪酸 (PLFA) 的碳同位素: 取收集有 POM 的 GFF 膜经冷冻干燥后, 利用 Bligh-Dyer 方法 ${ }^{[23]}$, 经 过 $\mathrm{BD}$ 相提取液溶解, 离心震荡分液, 旋转蒸发, 层析柱过滤, 获得极性脂, 再经过㿝化, 然后加人甲醇盐酸溶 液形成脂肪酸甲酯(FAME), 萃取 FAME 相, 最后利用气相色谱-同位素质谱仪 (GC-c-IRMS) ( Thermo Finnigan, Breman, Germany) 获得 PLFA 同位素比值 $\left(\delta^{13} \mathrm{C}\right)$. 同位素 $\delta$ 值 $(\% 0)$ 表示:

$$
\delta=\left(R_{\text {sample }} / R_{\text {standard }}-1\right) \times 1000
$$


式中, $R$ 为同位素丰度比, $R_{\text {sample }}$ 为样品中的同位素丰度比, $R_{\text {standard }}$ 为标准物质的同位素丰度比. 本文主要应 用的是碳同位素比值即 $\delta^{13} \mathrm{C}$, 标准碳稳定同位素 $\delta^{13} \mathrm{C}$ 参照海相碳酸盐岩标准 (VPDB, Vienna Pee Dee Belemnite). 所有样品重复分析 2 次以上. 为确保仪器分析的一致性, 每测定 5 10 个样品即分析 1 2 个标样. 同 位素与生物量的相关性采用 SPSS 20.0 软件进行分析.

\section{2 结果与分析}

\section{1 浮游生物群落结构分析}

样品中共发现浮游植物 24 种, 隶属 6 个门, 蓝藻门、隐藻门、硅藻门、裸藻门、绿藻门和甲藻门. 其中绿 藻门种类最多, 占 $37.50 \%$, 其次是蓝藻门和硅藻门, 分别占 $16.67 \%$, 甲藻门最少, 仅占 $4.17 \%$. 在数量上占绝 对优势的是蓝藻门, 约占总密度的 $62.05 \%$, 其次是隐藻门 ( $12.42 \%$ ) 和硅藻门 ( 7.95\%), 绿藻门种类虽然最 多, 但是相对密度仅为 $7.92 \%$ (表 2). 此外, 蓝藻门中几乎未发现铜绿微囊藻、水华微囊藻、惠氏微囊藻及微 小微囊藻, 主要为其他微囊藻.

表 2 实验期间浮游植物种类与数量变化

Tab.2 Changes of phytoplankton species and quantity during the experiment

\begin{tabular}{|c|c|c|c|c|c|c|}
\hline 门类 & 种类数 & 种类比例 $/ \%$ & 密度范围 $/\left(\times 10^{4}\right.$ cells $\left./ \mathrm{L}\right)$ & 平均密度 $/\left(\times 10^{4}\right.$ cells $\left./ \mathrm{L}\right)$ & 相对密度/\% & 优势种 \\
\hline 蓝藻门 & 4 & 16.67 & $0.06 \sim 71.02$ & 18.49 & 62.05 & 其他微囊藻 \\
\hline 隐藻门 & 3 & 12.50 & $1.01 \sim 6.11$ & 3.70 & 12.42 & 啮蚀隐藻 \\
\hline 硅藻门 & 4 & 16.67 & $0.06 \sim 7.47$ & 2.37 & 7.95 & 小环藻 \\
\hline 裸藻门 & 3 & 12.50 & $0.45 \sim 4.30$ & 1.75 & 5.87 & 裸藻 \\
\hline 绿藻门 & 9 & 37.50 & $0.22 \sim 10.24$ & 2.36 & 7.92 & 小球藻 \\
\hline 甲藻门 & 1 & 4.17 & $0 \sim 2.04$ & 1.13 & 3.79 & 多甲藻 \\
\hline 总计 & 24 & - & $1.80 \sim 101.18$ & 29.80 & 100.00 & - \\
\hline
\end{tabular}

甲壳类浮游动物共鉴别出 6 个属, 分别为哲水蚤、虫状溞、象鼻溞、网纹溞、无节幼体、剑水蚤 (表 3 ). 数量 最多的是象鼻溞, 最小值为 $6.67 \mathrm{ind} . / \mathrm{L}$, 最大值为 $161.33 \mathrm{ind} . / \mathrm{L}$; 其次是网纹溞和虫状泽, 网纹溞数量最小值为 $0.67 \mathrm{ind} . / \mathrm{L}$, 最大值是 $5.33 \mathrm{ind} . / \mathrm{L}$; 蚤状溞最小值为 $0.67 \mathrm{ind} . / \mathrm{L}$, 最大值为 $2.67 \mathrm{ind} . / \mathrm{L}$; 数量最少的是哲水蚤和 剑水蚤, 只在第 $3 \mathrm{~d}$ 时出现, 数量为 $0.67 \mathrm{ind} . / \mathrm{L}$. 象鼻溞作为优势种群 $(57 \% \sim 100 \%)$, 在所有桶均有检出. 象鼻 溞在处理组中的数量显著高于对照组中的数量 $(P<0.01)$. 无节幼体仅在 1 个桶中检出. 虫状溞仅在对照组的 1 个桶中检出, 在处理组的 2 个桶均有检出. 网纹泽在对照组也仅有 1 个桶检出, 在处理组 3 个桶中均有检出.

虫状溞、象鼻溞和网纹溞数量随时间的变化趋势存在很大的差异. 从数量上看, 象鼻溞占据绝对优势; 从第 $0 \sim 6 \mathrm{~d}$, 象鼻溞数量呈直线增加, 网纹溞数量先增加后降低, 蚤状溞是先降低后增加; 第 $6 \sim 12 \mathrm{~d}$, 象鼻溞 数量不断减少, 而网纹溞和蚤状溞数量变化趋势一致, 都是先减少后增加 (图 1).

表 3 实验期间甲壳类浮游动物种类与数量变化

Tab.3 Changes of species and quantity of planktonic crustaceans during the experiment

\begin{tabular}{|c|c|c|c|c|c|c|}
\hline 时间 & $\begin{array}{l}\text { 哲水蚤/ } \\
\text { (ind./L) }\end{array}$ & $\begin{array}{l}\text { 蚤状溞/ } \\
\text { (ind./L) }\end{array}$ & $\begin{array}{l}\text { 象鼻溞/ } \\
\text { (ind./L) }\end{array}$ & $\begin{array}{l}\text { 网纹溞/ } \\
\text { (ind./L) }\end{array}$ & $\begin{array}{c}\text { 无节幼体/ } \\
\text { (ind./L) }\end{array}$ & $\begin{array}{l}\text { 剑水蚤/ } \\
\text { (ind./L) }\end{array}$ \\
\hline 第 $0 \mathrm{~d}$ (初始值) & - & $2.00 \pm 0.46$ & $6.67 \pm 1.15$ & $0.67 \pm 0.15$ & $0.67 \pm 1.15$ & - \\
\hline 第 $1 \mathrm{~d}$ & - & $1.33 \pm 0.31$ & $21.33 \pm 6.42$ & $2.67 \pm 0.15$ & - & - \\
\hline 第 $3 \mathrm{~d}$ & $0.67 \pm 1.15$ & $0.67 \pm 0.15$ & $100.00 \pm 22.27$ & $5.33 \pm 1.11$ & - & $0.67 \pm 1.15$ \\
\hline 第 $6 \mathrm{~d}$ & - & $2.67 \pm 0.31$ & $161.33 \pm 34.07$ & $1.33 \pm 0.15$ & $0.67 \pm 1.15$ & - \\
\hline 第 $9 \mathrm{~d}$ & - & $0.67 \pm 0.15$ & $56.00 \pm 14.42$ & - & - & - \\
\hline 第 $12 \mathrm{~d}$ & - & $2.00 \pm 0.23$ & $12.67 \pm 4.62$ & $6.00 \pm 1.21$ & $1.33 \pm 2.31$ & - \\
\hline
\end{tabular}

一表示未检出. 


\subsection{PLFA 的 $\delta^{13} \mathrm{C}$ 值变化}

根据相关文献, 实验所提取的 PLFA 中, $\mathrm{i}-\mathrm{C} 15 、 \mathrm{C} 16: 1 \omega 7$ 、n-C16、C18 $: 1 \omega 7$ 、n-C18 来源于 细菌, 而 $\mathrm{C} 18: 2 \omega 6$ 主要来源于绿藻或硅藻 ${ }^{[8]}$. 细菌和绿藻/硅藻的 PLFA 的 $\delta^{13} \mathrm{C}$ 值变化趋势 相同 (图 2), 在第 $1 \mathrm{~d}$ 时达到最大值, 但是细菌

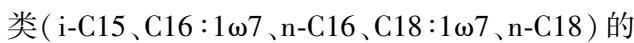
$\delta^{13} \mathrm{C}$ 值增长幅度远大于绿藻/硅藻的 PLFA $(\mathrm{C} 18: 2 \omega 6)$ 的 $\delta^{13} \mathrm{C}$ 值增长幅度;之后, 细菌和绿 藻/硅藻的 $\delta^{13} \mathrm{C}$ 值都开始不断地下降, 最终与未 加人 ${ }^{13} \mathrm{C}$ 标记葡萄糖的对照组样品的 $\delta^{13} \mathrm{C}$ 值 接近.

\section{$2.3 \mathrm{DOM} 、 \mathrm{POM} 、$ 细菌、绿藻与浮游动物的 $\delta^{13} \mathrm{C}$ 值变化}

POM 与 DOM 变化趋势有显著差异, POM

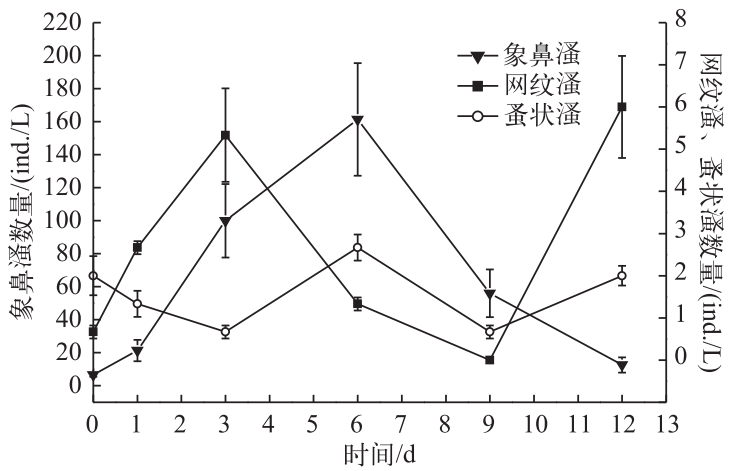

图 1 甲壳类浮游动物数量随时间的变化

Fig.1 Variation of planktonic crustaceans number over time

的变化幅度比较大, 而 DOM 变化幅度比较平缓 (图 3). 未加人 ${ }^{13} \mathrm{C}$ 标记葡萄糖时 (对照组), POM 和 DOM 的 $\delta^{13} \mathrm{C}$ 值分别为 $-13.99 \%$ 和 $-14.84 \%$. 加人葡萄糖后, $\mathrm{POM}$ 的 $\delta^{13} \mathrm{C}$ 值在第 $1 \mathrm{~d}$ 即达到峰值, 为 $2322.149 \%$, 之 后就开始呈下降趋势, 在第 $12 \mathrm{~d}$ 时达到 $260.19 \%$. 而 DOM 的 $\delta^{13} \mathrm{C}$ 值变化极为平缓, 从第 $1 \sim 6 \mathrm{~d}$ 缓慢增加, 到第 $6 \mathrm{~d}$ 达到了最大值, 为 $211.99 \%$, 之后开始缓慢下降. 哲水虫、象鼻溞、虫状溞 3 种浮游动物的 $\delta^{13} \mathrm{C}$ 值变 化趋势基本一致,表明其碳的来源基本相同. 未加人 ${ }^{13} \mathrm{C}$ 标记的葡萄糖时 (对照组), 哲水蚤、象鼻溞和蚤状溞 的 $\delta^{13} \mathrm{C}$ 值分别为 $-23.39 \%$ 、- $23.88 \%$ 和 $-21.43 \%$. 在加人 ${ }^{13} \mathrm{C}$ 标记的葡萄糖 $1 \mathrm{~d}$ 之后, 哲水蚤、象鼻溞和蚤状 溞的 $\delta^{13} \mathrm{C}$ 值迅速增加,第 $3 \mathrm{~d}$ 时均达到最大值,分别为 $1650.15 \%$ 、 $2152.02 \%$ 和 $2473.78 \%$; 第 $3 \mathrm{~d}$ 之后哲水 蚤、象鼻溞和蚤状溞的 $\delta^{13} \mathrm{C}$ 值持续下降,第 $12 \mathrm{~d}$ 降到最低,分别为 $927.17 \%$ 、697.14\% 和 $598.87 \%$. 以上结果 表明, 浮游动物与细菌和 POM 等的同位素峰值出现时间存在着一定的时间差. 整体而言, 浮游动物的 $\delta^{13} \mathrm{C}$ 最高值出现在第 $3 \mathrm{~d}$, 晚于 POM 最高值的出现时间 (第 $1 \mathrm{~d}$ ), 将以上结果与 DOM 的 $\delta^{13} \mathrm{C}$ 值并未出现显著升 高趋势的结果相联系, 可知细菌能够快速利用投加的葡萄糖, 并将其部分转化为 POM, 随后浮游动物很可能 优先利用了以 DOM 为主要碳源的细菌. 这一点将在随后进行详细讨论.

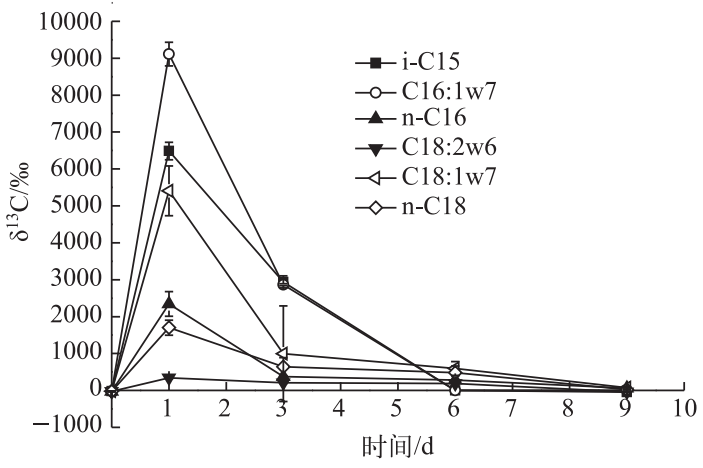

图 2 PLFA 的 $\delta^{13} \mathrm{C}$ 值 变化趋势

Fig.2 Change of the stable isotope ratios of PLFA

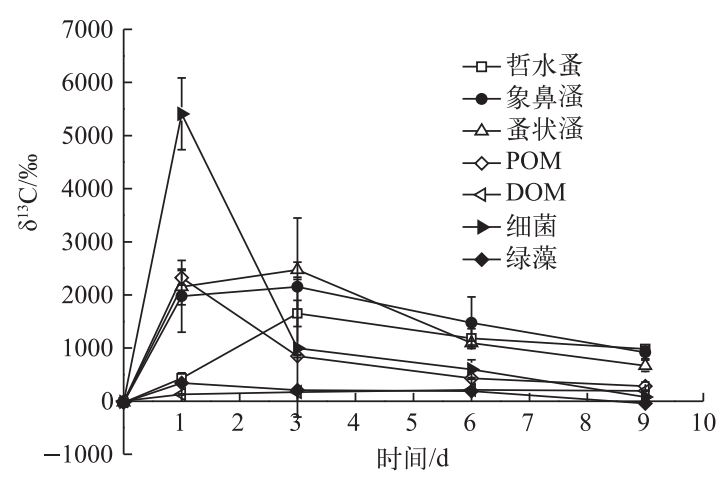

图 3 细菌、绿藻、浮游动物以及 $\mathrm{DOM}$ 、 $\mathrm{POM}$ 的 $\delta^{13} \mathrm{C}$ 值变化趋势

Fig. 3 Changes of $\delta^{13} \mathrm{C}$ of bacteria, chlorophyta, planktonic crustaceans, DOM and POM 
POM 和 DOM 的 $\delta^{13} \mathrm{C}$ 值变化情况 (图 3), 为了进一步表明它们之间的相关性, 对浮游动物、细菌、绿藻的 $\delta^{13} \mathrm{C}$ 值与 POM 及 DOM 的 $\delta^{13} \mathrm{C}$ 值进行相关分析, 结果见表 4. 细菌与 POM 的 $\delta^{13} \mathrm{C}$ 值变化趋势非常相似, POM 的 $\delta^{13} \mathrm{C}$ 值与绿藻 $\delta^{13} \mathrm{C}$ 值并不相似 (图 3), 细菌与 POM 也呈极显著相关 $(P<0.01)$, POM 与绿藻存在显 著相关性 (表 4), 二者结果相呼应. 虫状溞与象鼻溞呈极显著相关 $(P<0.01)$, DOM 与哲水蚤呈显著相关 $(P<$ $0.05)$, 绿藻均与蚤状溞、象鼻溞以及 POM 存在显著相关性 $(P<0.05)$.

表 4 浮游动物、细菌、绿藻的 $\delta^{13} \mathrm{C}$ 值与 DOM 及 $\mathrm{POM}$ 的 $\delta^{13} \mathrm{C}$ 值的相关分析

Tab.4 Pearson correlation coefficient of $\delta^{13} \mathrm{C}$ of planktonic crustaceans, bacteria, chlorophyta, DOM and POM

\begin{tabular}{|c|c|c|c|c|c|c|c|}
\hline & 哲水蚤 & 象鼻溞 & 蚤状溞 & POM & DOM & 绿藻 & 细菌 \\
\hline 哲水蚤 & 1.000 & & & & & & \\
\hline 象鼻溞 & 0.677 & 1.000 & & & & & \\
\hline 蚤状溞 & 0.584 & $0.966^{\text {** }}$ & 1.000 & & & & \\
\hline POM & -0.036 & 0.702 & 0.742 & 1.000 & & & \\
\hline DOM & $0.824^{*}$ & 0.646 & 0.452 & 0.127 & 1.000 & & \\
\hline 绿藻 & 0.248 & $0.850^{*}$ & $0.845^{*}$ & $0.8611^{*}$ & 0.295 & 1.000 & \\
\hline 细菌 & -0.205 & 0.574 & 0.618 & $0.984^{* *}$ & 0.002 & $0.815^{*}$ & 1.000 \\
\hline
\end{tabular}

*表示显著相关, $P<0.05, * *$ 表示极显著相关, $P<0.01$.

\section{3 讨论}

\section{1 细菌对外源有机碳的利用}

磷脂脂肪酸作为生物细胞膜的重要组成部分, 具有结构多样性和很高的生物学特异性, 是非常有效的 特定生物标志物 ; 同时, 外源与内源 DOC 具有不同的碳稳定同位素特征, 通过细菌和不同来源有机物的碳稳 定同位素的分析,可以区分外源与内源 DOC 对细菌碳源的贡献 ${ }^{[24]}$. 因此,磷脂脂肪酸谱图分析与稳定同位 素技术相结合, 可以为确定生物种群间的相互关系及对整个生态系统的能量流动进行准确定位 ${ }^{[25]}$. Rajendran 等 ${ }^{[26]}$ 用 PLFA 技术研究了日本某富营养化湖泊沉积物中的生物量. 检测出的磷脂脂肪酸大多数 属于细菌类群,多聚非饱、脂肪酸及长链脂肪酸较少. 本研究中将 ${ }^{13} \mathrm{C}$ 标记的葡萄糖作为碳源, 通过提取磷脂

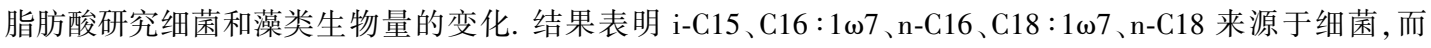
$\mathrm{C} 18: 2 \omega 6$ 主要来源于绿藻或硅藻 ${ }^{[8]}$, 并得出细菌和藻类的 $\delta^{13} \mathrm{C}$ 值, 则 ${ }^{13} \mathrm{C}$ 富集的 PLFA 所代表的生物就是参 与了 ${ }^{13} \mathrm{C}$ 标记葡萄糖代谢的生物 ${ }^{[27]}$.

进人水生生态系统中的外源有机碳主要包括 DOC 和 POC, 其中大部分外源碳以 DOC 形式进人水体. 外 源 DOC 可作为碳源为浮游细菌所吸收, 增加浮游细菌的生物量从而进人到湖泊食物网当中. Kritzberg 等 ${ }^{[28]}$ 在一个臭营养并富含腐殖质的湖泊中的研究结果表明, 该湖 $40 \%$ $80 \%$ 的细菌生物量的碳源来自于外源性 有机碳. 本研究中, 随着 ${ }^{13} \mathrm{C}$ 标记的葡萄糖的加人, 细菌、POM 和浮游动物的 $\delta^{13} \mathrm{C}$ 值几乎同时急剧增加 (图 3 ), 且前 $3 \mathrm{~d}$ 趋势一致, 说明浮游动物同时利用了细菌与 POM. 从 $\delta^{13} \mathrm{C}$ 值增长的幅度来看, 外源 DOC 加人实 验组后, 细菌能够极其迅速地分解利用 DOC, 继而通过细菌吸收利用后形成细胞颗粒, 随之生成 DOC 与 $\mathrm{POC}$, 最后通过浮游动物摄食再进入传统食物链 ${ }^{[29-30]}$. 因此, 本实验中 $\mathrm{POM}$ 的 $\delta^{13} \mathrm{C}$ 值也随细菌显示出快速 增加的趋势 (图 3). 外源性 DOC 本身可作为一种基质参与水生微生物的新陈代谢. Carignan 等 ${ }^{[31]}$ 研究表明 细菌可利用外源 DOC 进行呼吸作用. 本实验中, 细菌的 $\delta^{13} \mathrm{C}$ 值在 $1 \mathrm{~d}$ 之后不断下降 (图 3), 这是由于细菌通 过呼吸作用, 将 ${ }^{13} \mathrm{C}$ 以 $\mathrm{CO}_{2}$ 的形式不断释放的结果 ${ }^{[29-30]}$.

\section{2 浮游动物对外源有机碳的利用方式和途径}

如果外源性碳首先被初级生产者或初级消费者吸收利用, 外源性碳则由细菌将陆源碳传递到食物网上 一级, 即通过上行效应影响食物链 ${ }^{[32]}$. 第 $1 \mathrm{~d}$ 后, 当甲壳类浮游动物的 $\delta^{13} \mathrm{C}$ 值仍在增加之时, 细菌和 POM 的 $\delta^{13} \mathrm{C}$ 值已急剧下降, 说明甲壳类浮游动物摄食了细菌以及细菌的代谢产物 $\mathrm{POM}$ (图 3). 所选的 3 种甲壳类 浮游动物中哲水蚤属于桡足类, 而象鼻溞和蚤状溞属于枝角类, 且都是滤食性浮游动物, 从水中滤食细小的 
食物, 主要包括细菌、藻类和碎屑等 ${ }^{[33]}$. 第 $1 \mathrm{~d}$ 时, 象鼻溞和蚤状溞的 $\delta^{13} \mathrm{C}$ 值比哲水蚤的 $\delta^{13} \mathrm{C}$ 值大 (图 3), 且 POM 和细菌与象鼻溞和虫状溞相关性比与哲水蚤的相关性明显, DOM 与哲水蚤的相关性比与象鼻溞和 蚤状溞相关性明显 (表 4), 进一步表明了象鼻溞和虫状溞主要摄食细菌及细菌代谢的颗粒物, 而哲水蚤主要 摄食 DOM; 第 $3 \mathrm{~d}$ 时, 哲水蚤和象鼻溞、蚤状溞的 $\delta^{13} \mathrm{C}$ 值比较接近, 仍低于象鼻溞和蚤状溞的 $\delta^{13} \mathrm{C}$ 值, 说明 对外源有机碳的竞争中, 象鼻溞和虫状溞占据主导地位, 而哲水蚤相对弱一些. 以上结果表明细菌对枝角类 浮游动物的碳源有重要的影响. Banta 等 ${ }^{[34]}$ 用细菌悬浮液培养一种枝角类, 结果证实其孤䧳生殖世代达到 1600 多代. 而大多数哲水蚤通常被归为植食性桡足类, 但是实际上哲水蚤的食物构成中也有部分是来自于 其他有机颗粒物 ${ }^{[35]}$. 经典食物网的研究结果表明, 浮游动物利用外源有机碳的途径主要有: 1 ) 直接摄食有 机碎屑; 2) 摄食利用了外源有机碳的异养细菌 ${ }^{[7]}$. 而浮游动物利用内源有机碳 (浮游植物) 的途径主要有: 1) 直接摄食浮游植物;2) 摄食浮游植物有机碎屑; 3 ) 摄食利用了浮游植物碳源的细菌.

本研究中甲壳类浮游动物的 $\delta^{13} \mathrm{C}$ 值与 $\mathrm{POM}$ 的 $\delta^{13} \mathrm{C}$ 值变化趋势相似, 极有可能是异养细菌快速利用 DOC 后代谢产生 POM 所引起的结果. 实验中, 绿藻的 $\delta^{13} \mathrm{C}$ 值在加人葡萄糖时, 由 $-27.07 \% 0$ 增加到 $342.44 \%$ (图 3), 之后, 绿藻的 $\delta^{13} \mathrm{C}$ 值与溶解性有机物 ( DOM) 的 $\delta^{13} \mathrm{C}$ 值较接近 (图 3). 这说明了两种可能性: (1)浮游 植物可能利用了细菌产生的富含 ${ }^{13} \mathrm{C}$ 的 $\mathrm{CO}_{2}$, (2) 实验添加的葡萄糖参与到了浮游植物的光合作用过程中.

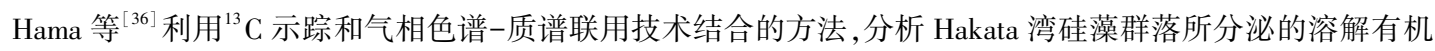
物部分, 发现在 $12 \mathrm{~h}$ 的培养过程中, 中性醛糖占释放的 DOC 的 47\% 59\%, 其中葡萄糖是最主要的成分, 且 葡萄糖主要以葡聚糖的形态释放. 相对于由浮游植物固定后经各种途径转换后再释放到水体中的溶解有机 物, 由浮游植物直接释放的溶解有机物以碳水化合物为主, 其中葡萄糖又是最主要的成分 ${ }^{[36-37]}$, 更容易被细 菌所利用. 总体而言, 本研究采集的抚仙湖水样中, 浮游植物的平均密度小于文献报道的抚仙湖的平均密 度 ${ }^{[38]}$, 说明采样点营养水平较低, 浮游植物贡献的有机碳量并不高.

\section{3 外源有机碳对细菌和浮游动物的贡献}

一般而言, 细菌更喜欢利用低碳氮比 $(\mathrm{C}: \mathrm{N})$ 、易降解的内源 DOC, 但是外源性 DOC 也是细菌生长、代谢 的重要碳源. Berggren 等 ${ }^{[39]}$ 研究发现, 低分子量的外源有机碳对细菌、原生动物和后生动物二级生产力的贡 献率分别为 $80 \%$ 、 $54 \%$ 和 $23 \%$, 通过摄食浮游细菌, 这部分碳源能被有效地传递到更高营养级别. 有研究发 现在贫营养湖泊中, 外源性有机碳对浮游动物碳源的贡献率为 $22 \% \sim 75 \%{ }^{[40]}$. 本实验中, 绿藻的 $\delta^{13} \mathrm{C}$ 值与浮 游动物并不接近, 这可能与加人的葡萄糖的高生物可利用性有关. 尽管葡萄糖也能够参与浮游植物的光合 作用过程中, 但是它更可能被细菌优先利用. 在初级生产力较低的塞营养湖泊中, 细菌与浮游植物具有营养

盐竞争关系. 在塞营养条件下, 细菌在与浮游植物竞争摄取磷方面占据优势地位 ${ }^{[31]}$. 抚仙湖地处高海拔地 区, 紫外辐射强烈. 胞外酶和强紫外辐射可以提高外源性 DOC 的细菌可利用性. 细菌是吞噬性微生物 (如鞭 毛虫和纤毛虫) 和滤食性浮游动物 (如大型枝角类) 的良好食物, 而桡足类可以选择性摄食纤毛虫和鞭毛虫. 因此, 外源 DOC 可通过被细菌转化为其生物量进人食物链, 并不断向更高营养级传递 ${ }^{[32]}$. 此外, 水力停留时 间对于水生生物对外源性碳的利用率会产生一定的影响. 抚仙湖属大型深水湖泊,水力停留时间比较长, 而 有机碳在水体中滞留的时间愈长, 被利用的机率愈高 ${ }^{[41]}$. 整体而言, 抚仙湖是较典型的贫营养湖泊, 初级生 产力较低, 内源贡献不足以支持浮游动物的生长活动. 因此, 外源有机碳对抚仙湖的食物网结构影响较大, 对浮游动物的碳源起到了重要贡献.

\section{4 结论}

通过 ${ }^{13} \mathrm{C}$ 标记的实验, 探讨抚仙湖甲壳类浮游动物对外源有机碳的利用途径. 结果表明: 1) 外源有机碳 首先被细菌和浮游动物吸收利用;2) 细菌吸收的外源碳一部分通过自身的代谢作用形成细胞颗粒, 浮游动 物通过摄食颗粒性有机物 (POM), 而获得这部分的碳源, 而细菌产生的 $\mathrm{CO}_{2}$ 可能会被浮游植物利用. 研究结 果证明在初级生产力低、内源碳不足以供给消费者生长需求的贫营养水体中, 外源有机碳对浮游动物的碳 源起到了重要的支撑作用.

\section{5 参考文献}

[ 1 ] Richardson JS, Zhang Y, Marczak LB. Resource subsidies across the land-freshwater interface and responses in recipient 
communities. River Research and Applications, 2010, 26( 1 ) : 55-66.

[ 2 ] Wetzel RG. Limnology: Lake and river ecosystems. Eos Transactions American Geophysical Union, $2001,21(2)$ : 1-9.

[ 3 ] Grey J, Jones RI, Sleep D. Stable isotope analysis of the origins of zooplankton carbon in lakes of differing trophic state. Oecologia, 2000, 123(2) : 232-240.

[ 4 ] Pace ML, Cole JJ, Carpenter SR et al. Whole-lake carbon-13 additions reveal terrestrial support of aquatic food webs. Nature, 2004, 427(6971): 240-243.

[ 5 ] Cole JJ, Carpenter SR, Pace ML et al. Differential support of lake food webs by three types of terrestrial organic carbon. Ecology Letters, 2006, 9(5) : 558-568.

[6] Fry B. Stable isotope ecology. New York: Springer, 2006: 204-212.

[ 7 ] Boschker HTS, Middelburg JJ. Stable isotopes and biomarkers in microbial ecology. FEMS Microbiology Ecology, 2002, 40(2): 85-95.

[ 8 ] Boschker HTS, Kromkamp JC, Middelburg JJ. Biomarker and carbon isotopic constraints on bacterial and algal community structure and functioning in a turbid, tidal estuary. Limnology and Oceanography, 2005, 50(1): 70-80.

[ 9 ] Liu Zhanfeng, Li Liangjun, Ren Zheng et al. The advance in isotope labeled glucose. Nuclear Techniques, 2013, 36( 1 ) : 103021-103027. [ 刘占峰, 李良君，任征等. 同位素标记葡萄糖的研究进展. 核技术，2013，36 ( 1 ) : 103021-103027.]

[10] Ziegler SE, White PM, Wolf D et al. Tracing the fate and recycling of 13C-labeled glucose in soil. Soil Science, 2005 , 170 (10): 767-778.

[11] Shi Ningning, Xu Hong, Yao Jun et al. Investigation of metabolic routes to $\gamma$-Poly (glutamic acid) by ${ }^{13}$ C-labeled glucose as medium carbon source. Chinese Journal of Process Engineering, 2007, 7(1): 145-148. [石宁宁, 徐虹, 姚俊等. 利 用 ${ }^{13} \mathrm{C}$ 标记葡萄糖分析 $\gamma$-聚谷氨酸的代谢途径. 过程工程学报, 2007, 7(1): 145-148.]

[12] Wang Lin, Tang Jinyan, Liu Yu et al. Study on the vulnerability of environment in Fuxian Lake. Hubei Agricultural Sciences, 2012, 51(14) : 2965-2970. [王林, 唐金焰, 刘宇等. 抚仙湖生态环境脆弱性分析研究. 湖北农业科学, $2012, \mathbf{5 1}(14):$ 2965-2970.]

[13] Nanjing Institute of Geography and Limnology, Chinese Academy of Sciences ed. Lake Fuxian. Beijing: Ocean Press, 1990. [中国科学院南京地理与湖泊研究所. 抚仙湖. 北京: 海洋出版社, 1990.]

[14] Gao Wei, Chen Yan, Xu Min et al. Trend and driving factors of water quality change in Lake Fuxian( 1980-2011). J Lake $S c i, 2013,25(5)$ : 635-642. DOI: 10.18307/2013.0503. [高伟, 陈岩, 徐敏等. 抚仙湖水质变化( 1980-2011)趋势 和驱动力分析. 湖泊科学, 2013, 25(5):635-642.]

[15] Pan Jizheng, Xiong Fei, Li Wenchao et al. Spatial-temporal dynamic changes of the water transparency and their influencing factors in Lake Fuxian, Yunnan Province. J Lake Sci, 2008, 20( 5) : 681-686. DOI: 10.18307/2008.0519. [潘继 征, 熊飞, 李文朝等. 云南抚仙湖透明度的时空变化及影响因子分析. 湖泊科学, 2008, 20(5):681-686.]

[16] Lei Ligai, Ma Xiaozhen, Wei Fuxiang et al. Research progress of determination of total nitrogen and total phosphorus in seawater. Hebei Journal of Industrial Science and Technology, 2011, 28(1): 72-76. [雷立改, 马晓珍, 魏福祥等. 水中 总氮、总磷测定方法的研究进展. 河北工业科技, 2011, 28(1) : 72-76.]

[17] Pápista É, Ács É, Böddi B. Chlorophyll-a determination with ethanol-A critical test. Hydrobiologi, 2002, 485 ( 123): 191-198.

[18] Utermöhl H. Neue wege in der quantitativan erfassung des planktons ( Mit besondere Berü-cksichtigung des Ultraplanktons ). Verh Int Verein Theor Angew Limnol, 1931, 5: 567-595.

[19] Zhang Zongshe, Huang Xiangfei eds. Research methods of freshwater plankton. Beijing: Science Press, 1991.[章宗涉, 黄祥飞. 淡水浮游生物研究方法. 北京: 科学出版社, 1991.]

[20] Hu Hongjun, Wei Yinxin eds. The freshwater algae of China-Systematics, taxonomy and ecology. Beijing: Science Press, 2006. [ 胡鸿钧, 魏印心. 中国淡水藻类——系统、分类及生态. 北京: 科学出版社, 2006.]

[21] Research Group of Carcinology, Institute of Zoology, Academia Sinica ed. Fauna sinica crustacea • freshwater copepods Beijing: Science Press, 1979. [中国科学院动物研究所甲壳动物研究组. 中国动物志甲壳纲: 淡水桡足类. 北京: 科 学出版社, 1979.]

[22] Jiang Xiezhi, Du Nanshan eds. Fauna Sinica Crustacea - Freshwater Cladocera. Beijing: Science Press, 1979.[蒋燮治, 堵南山. 中国动物志甲壳纲: 淡水枝角类. 北京: 科学出版社, 1979.] 
[23] Bligh EG, Dyer WJ. A rapid method of total lipid extraction and purification. Canadian Journal of Biochemistry and Physiology, 1959, 37(8): 911-917.

[24] Van den Meersche KK, Van Rijswijk P, Karline S et al. Autochthonous and allochthonous contributions to mesozooplankton diet in a tidal river and estuary: Integrating carbon isotope and fatty acid constraints. Limnology and Oceanography, $2009, \mathbf{5 4}(1): 62-74$.

[25] Zhao Dayong, Yan Wenming, Feng Jingwei et al. Applications of phospholipid fatty acid analysis in the microbial ecology studies of lake sediment. Chemistry \& Bioengineering, 2009, 26(12): 17-20. [ 赵大勇, 燕文明, 冯景伟等. 磷脂脂肪 酸分析在湖泊沉积物微生物生态学研究中的应用. 化学与生物工程, 2009, 26(12): 17-20.]

[26] Rajendran N, Matsuda O, Imamura N et al. Variation in microbial biomass and community structure in sediments of eutrophic bays as determined by phospholipid ester-linked fatty acids. Applied and Environmental Microbiology, $1992, \mathbf{5 8}$ (2) : 562-571.

[27] Ge Yuan, He Jizheng, Zheng Yuanming et al. Stable isotope probing and its applications in microbicalecology. Acta Ecologica Sinica, 2006, 26(5) : 1574-1582. [ 葛源, 贺纪正, 郑袁明等. 稳定性同位素探测技术在微生物生态学研究中 的应用. 生态学报, 2006, 26(5): 1574-1582.]

[28] Kritzberg ES, Cole J, Pace ML et al. Bacteria growth on allochthonous carbon in humic and nutrient-riched lakes: Results from whole-lake ${ }^{13} \mathrm{C}$ addition experiments. Ecosystems, 2006, 9(3): 489-499.

[29] Azam F, Fenchel T, Field J et al. The ecological role of water-column microbes in the sea. Marine Ecology Progress Series, $1983, \mathbf{1 0}(3):$ : 257-263.

[ 30] Jansson M, Persson L, De Roos AM et al. Terrestrial carbon and intraspecific size-variation shape lake ecosystems. Trends in Ecology and Evolution, 2007, 22(6) : 316-322.

[31] Carignan R, Planas D, Vis C. Planktonic production and respiration in oligotrophic shield lakes. Limnology and Oceanography, 2000, 45(1): 189-199.

[32] Tang Yali, Cheng Dongmei, Liu Zhengwen et al. Differntial support of lake food webs by allochthonous organic carbon. Ecological Science, 2014, 33(1): 161-165. [ 唐雅丽, 程冬梅, 刘正文等. 外源性有机碳对淡水生态系统食物网的贡 献. 生态学报, 2014, 33(1): 161-165.]

[33] Institute of Animal, Chinese Academy of Science, crustaceans research group ed. Chinese animal. Beijing: Science Press, 1979. [中国科学院中国动物志委员会. 中国动物志. 北京: 科学出版社, 1979.]

[34] Banta AM. Population density as related to sexand to evolution in Cladocera. The American Naturalist, 1937, 71(732) : 34-49.

[35] Zhang Guangtao, Li Chaolun, Sun Song et al. Feeding habit of Calanussinicus (Crustacea: Copepoda) during spring and autumn in the Bohai Sea studied with herbivore index. Scientia Marina, 2006, 70(3) : 381-388.

[36] Hama T, Yanagi K. Production and neutral aldose composition of dissolved carbohydrates excreted by natural marine phytoplankton populations. Limnology and Oceanography, 2001, 46(8) : 1945-1955.

[37] Biddanda B, Benner R. Carbon, nitrogen, and carbohydrate fluxes during the production of particulate and dissolved organic matter by marine phytoplankton. Limnology and Oceanography, 1997, 42(3) : 506-518.

[38] Pan Jizheng, Xiong Fei, Li Wenchao et al. Structure distribution and it's impact factors of phytoplankton community in Fuxian Lake. Acta Ecological Sinica, 2009, 29(10): 5376-5385. [ 潘继征, 熊飞, 李文朝等. 抚仙湖浮游植物群落结 构、分布及其影响因子. 生态学报, 2009, 29(10): 5376-5385.]

[39] Berggren M, Strom L, Laudon H et al. Lake secondary production fueled by rapid transfer of low molecular weight organic carbon from terrestrial sources to aquatic consumers. Ecology Letters, 2010, 13(7) : 870-880.

[40] Yokokawa T, Nagata T. Linking bacterial community structure to carbon fluxes in marine environments. Journal of Oceanography, 2010, 66(1): 1-12.

[41] Algesten G, Sobek S, Bergstro MAK et al. Role of lakes for organic carbon cycling in the boreal zone. Global Change Biology, 2005, 10(1): 141-147. 